\title{
VENTRICULAR ESCAPE IN ACUTE RHEUMATISM
}

\author{
BY \\ ALAN C. KIRBY \\ From the Alder Hey Hospital and the Department of Child Health, University of Liverpool
}

Received July 20, 1948

Ventricular escape can be produced by depression of the sino-auricular node as a result of digitalis therapy, marked sinus arrhythmia, sinus bradycardia, or pressure on a hyperirritable carotid sinus, or by hyperirritability of the auriculo-ventricular node. The latter type is the one referred to here. It is differentiated from auriculo-ventricular dissociation due to complete heart block by the fact that the ventricles beat at the same or a more rapid rate than the auricles. There is no general agreement about the ultimate mechanism of its production. The most likely and usually accepted cause is irritation of the node by adjacent pathological changes, such as transient odema around a rheumatic nodule or cellular infiltration of the node with or without endarteritis in the small vessels supplying it (Gross and Fried, 1936; quoted by Stein and Bartlett, 1946). Stimulation of the sympathetic or paralysis of the vagus supply to the node consequent upon the same rheumatic process could have a similar effect. There is also no agreement as to its significance in prognosis. Dressler (1930) found that it occurs during the course of acute articular rheumatism. Stein and Bartlett (1946) state that it must not be regarded as an expression of the natural cardiac mechanism, that it is transient, and that it probably bears no relation to the outcome of acute rheumatism. They state, however, that once a complete heart block has been excluded it is reasonable to give a good prognosis. Wendkos and Noll (1944) had previously arrived at the same conclusion. Cutts (1937) does not concur but agrees with Richardson (1915) that auriculo-ventricular dissociation due to ventricular escape is not of itself serious but that it is frequently associated with severe infection or severe and chronic heart disease.

Two cases of acute rheumatism have recently been seen at Alder Hey Hospital exhibiting ventricular escape.

\section{CASE Notes}

Case 1. This patient was a girl of 11 years who had suffered with recurrent attacks of tonsillitis until the age of 7 , when her tonsils were removed. From that time until six days before admission to hospital she had no further attacks. She was sent home from school complaining of a sore throat and pain in the back and thighs. On the day of admission the pain in the legs, particularly the knees, was severe enough to make her cry if moved.

On examination the temperature was $99.4^{\circ} \mathrm{F}$., and the pulse rate 128 a minute. She was thin, pale, and apprehensive; there was no dyspnœa nor cyanosis. The throat was slightly injected with no visible tonsillar tissue and no membrane. The tonsillar glands were a little enlarged and tender. Both knees were painful on movement, which was. limited to $45^{\circ}$, and tender to touch. There was no redness or swelling and rheumatic nodules were not found. The pulse was generally regular with occasional periods of irregularity. The heart apex beat was in the fifth left intercostal space, $6 \mathrm{~cm}$. from the midline, the heart sounds were all softened and there were no murmurs. Auscultation revealed the same cardiac arrhythmia as the pulse, which was considered to be due to extrasystoles.

The condition was diagnosed as acute rheumatism and treatment was begun with sodium salicylate, 15 grains, and sodium bicarbonate, 20 grains, fourhourly; this was continued for four weeks.

On the day following admission pain in the knees was less, but she complained of a dull præcordial pain which was eased by cataplasma kaolin. The cardiac rhythm was regular; no change had taken place in the heart sounds. Two days after admission the pain in the legs and præcordium had gone; and her general condition had improved. The cardiac rhythm, however, was usually irregular except for brief periods. The rate was still 110 to 130 a minute; in spite of this rapid rate the irregularity was typical of extrasystoles. A cardiogram showed auriculo-ventricular dissociation, auricular rate 83 a minute, ventricular rate 107 a minute 


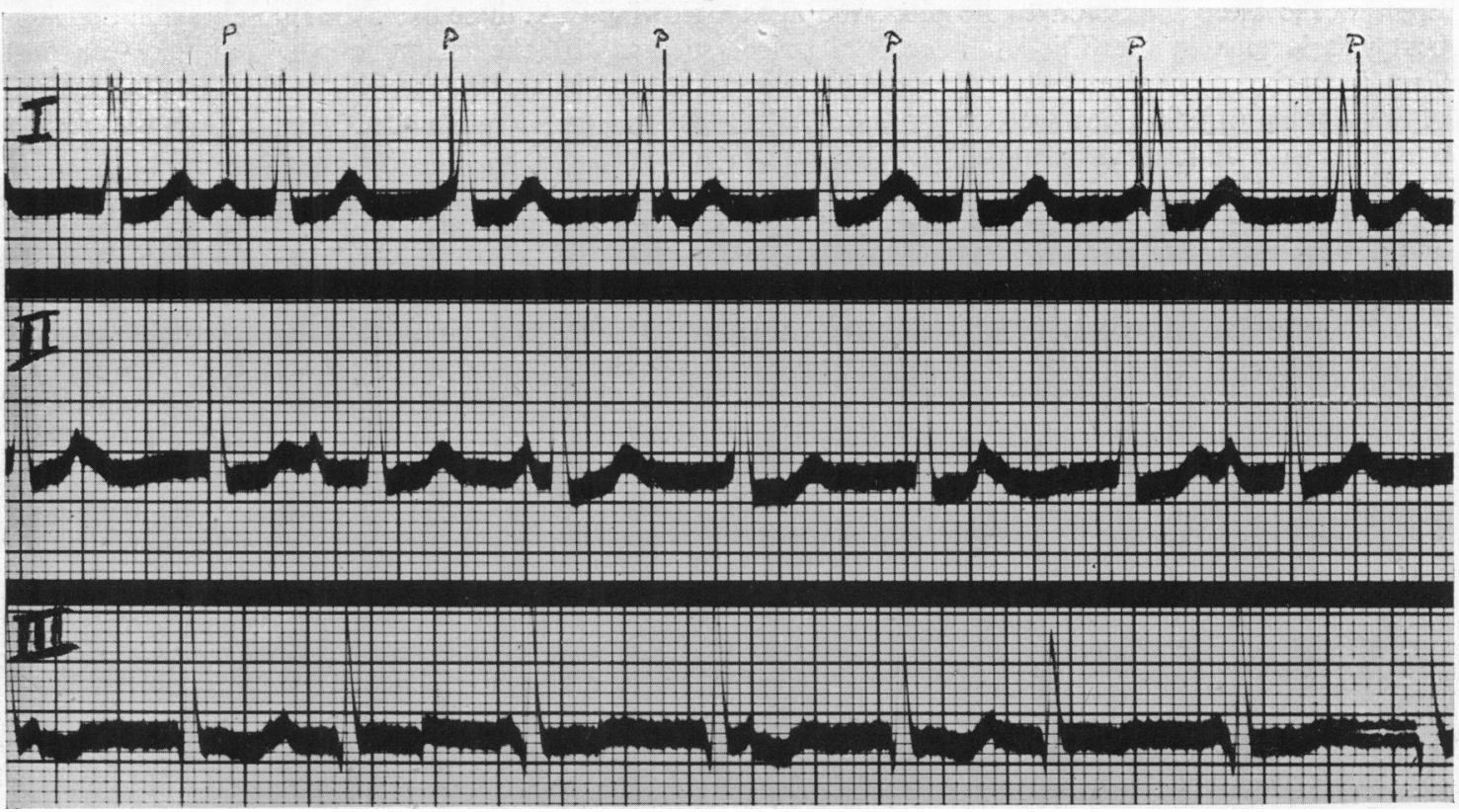

FIG. 1.-Case. 1. Ventricular escape. Auricular rate 83 a minute; ventricular rate 107 a minute.

(Fig. 1). On the fourth day the cardiac rhythm was quite regular at a rate of 92 a minute. The first apical sound was softened but the others were now *lear and much louder. The general condition continued to improve and by the end of another week the quality of all the heart sounds was good, but a soft localized apical systolic murmur had become evident. Five weeks after admission, cardiac irregularity typical of extrasystoles was again noted, the rate being 75 a minute. This was the only occasion on which irregularity had been found since the second day after admission. A cardiogram showed sinus arrythmia and two dissimilar ventricular extrasystoles. At the end of the sixth week in hospital she was regarded as convalescent and five weeks later she was discharged. The heart sounds were normal but the apical systolic murmur, still soft and localized, persisted. The cardiogram was normal. The E.S.R., which had been $92 \mathrm{~mm}$. in the first hour (Westergren) on admission, was now $5 \mathrm{~mm}$., and X-ray examination showed a normal cardiac outline.

Case 2. A girl, aged 8 years. Apart from scarlet fever at the age of five she had been well until 7 days before admission when she complained of severe pain behind both knees and was unable to walk. The pain subsided after 24 hours. For the next six days she complained of stiff knees on waking up in the mornings and occasional fleeting pains during the day. She was feverish for two to three days before admission.

On examination the temperature was $101^{\circ} \mathrm{F}$., and the pulse rate 124 a minute. She was flushed and the skin was hot and dry. There was a fading erythema marginatum on the front of the chest and abdomen. The tongue was furred but the throat appeared healthy. The movements of the knee joints were full and there was no swelling or redness. The pulse was regular, the heart apex beat in the fourth left intercostal space $6 \mathrm{~cm}$. from the midline, the pulmonary second sound accentuated, and there was a soft blowing apical and basal systolic murmur. No abnormality was found in the lungs or abdomen, and there were no rheumatic nodules though a few were found late in the illness on the wrists and elbows. A diagnosis of acute rheumatism with rheumatic carditis was made and treatment with calcium aspirin, 10 grains, t.i.d., was begun.

The temperature settled after two days and the sleeping pulse rate fell to about 80 a minute. X-ray examination showed the cardiac outline to be normal and the E.S.R. was $79 \mathrm{~mm}$. (Westergren). Progress was good for 4 weeks but choreiform movements, which continued for 2 weeks, were then noticed, and an aortic diastolic murmur was heard. The blood pressure in the arm was $100 / 70 \mathrm{~mm}$. Calcium aspirin was replaced by sodium salicylate, 15 grains, and sodium bicarbonate, 20 grains, four-hourly. 
Eight weeks after admission to hospital, the apex beat was located in the fifth left intercostal space $9 \mathrm{~cm}$. from the midline, and a late diastolic murmur of low rumbling quality was heard at the apex. The child was pale and apathetic during the succeeding 2 weeks then the temperature which had been normal for 8 weeks rose to $102 \cdot 4^{\circ} \mathrm{F}$., but settled again after 3 days. The pulse rate which had remained steady below 90 a minute increased to 120 to 130 a minute and the heart apex beat had become diffuse and tumultuous, $10 \mathrm{~cm}$. from the midline. A fleeting scratchy pericardial friction rub was audible in the second left interspace adjacent to the sternum; this was heard on and off for the next 7 days. The erythrocyte sedimentation rate was $83 \mathrm{~mm}$. and an $\mathrm{X}$-ray examination now showed marked generalized cardiac enlargement. The pulse rate continued between 120 and 130 a minute, and the blood pressure $105 / 20 \mathrm{~mm}$. Her general condition improved somewhat and remained so for another three weeks. She then suddenly became dyspnoic and ashen grey in colour. The pulse rate rose to around $150 \mathrm{a}$ minute, the rhythm being grossly irregular. Auricular fibrillation was diagnosed but a cardiogram showed A-V dissociation with regular auricular rhythm at a rate of 150 a minute. The ventricular rate was approximately the same with occasional slowing. At these times the sino-auricular node appeared to take charge of the ventricle, the $P-R$ interval being $0.2 \mathrm{sec}$. (Fig. 2). Digoxin was administered for 48 hours. On the next day slight pretibial œdema occurred and the liver, had become enlarged to two fingers' breadth below the costal margin and was very tender. The pulse rate had dropped to 100 a minute, the rhythm still being irregular, but the character of the irregularity had changed to one in which every sixth beat was dropped. Auscultation revealed a similar rhythm but whereas every sixth beat was missing at the pulse the normal heart sound was replaced at these times by a solitary faint clicking sound, only audible at the base. Later in the day the heart rate rose to between 130 and 140 a minute but otherwise no change occurred. On the following day the heart rate was regular but a loud pericardial friction rub was heard at the base of the heart. The liver was a little smaller and not so tender. A cardiogram showed that the rhythm was normal at the rate of $136 \mathrm{a}$ minute. The $P-R$ interval was prolonged to $0.2 \mathrm{sec}$. (Fig. 3). A week passed, her general condition was very poor but remained stationary. The cardiac rhythm was found to be irregular again with every sixth beat missing; rate 140 to 150 a minute. Auscultation revealed the same clicking sound

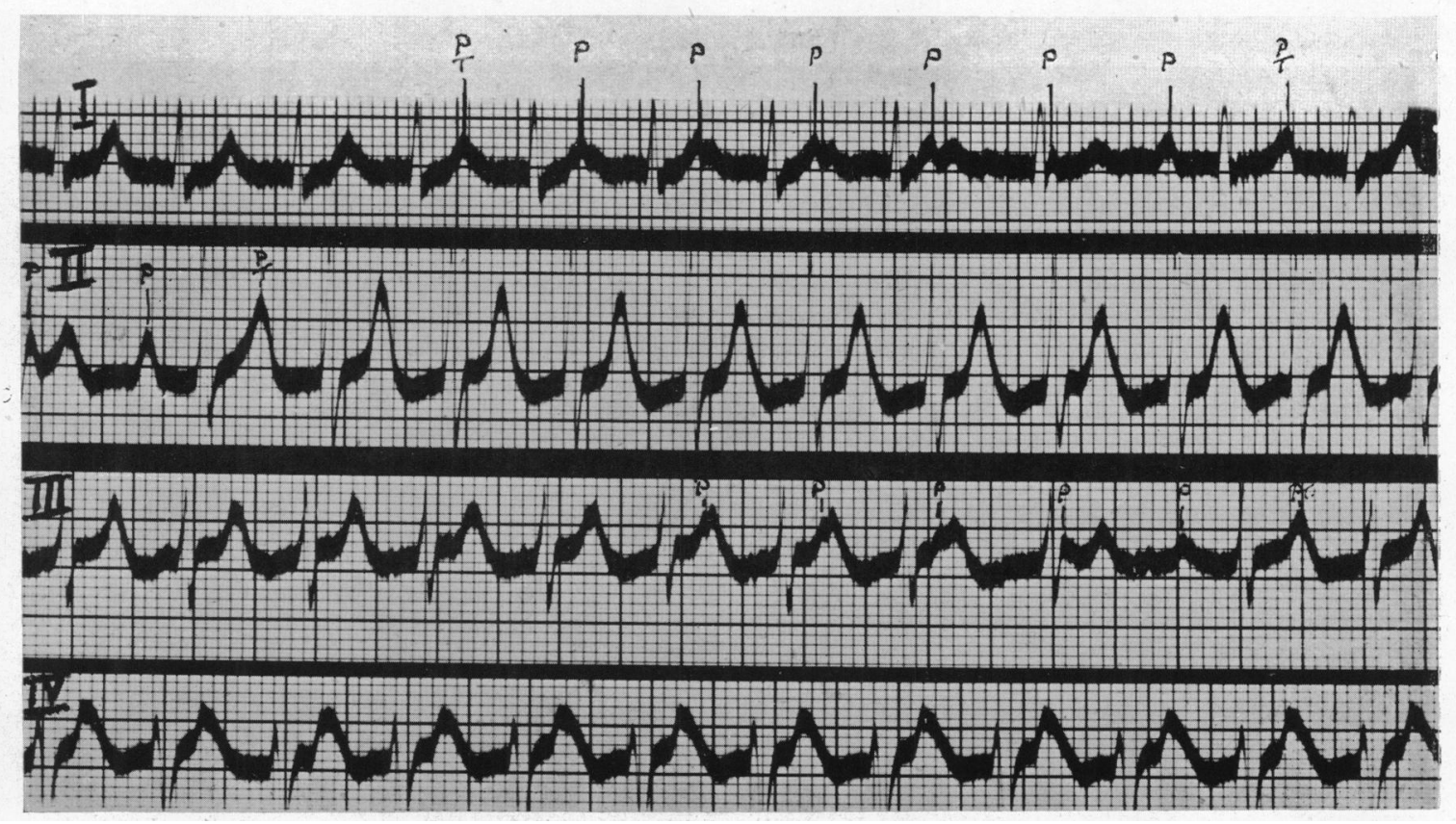

FIG. 2.-Case 2. Ventricular escape. Auricular rate 150 a minute; ventricular rate approximately the same with occasional slowing. When this occurs an isolated complex results which originates in the sino-auricular node the $\mathbf{P}-\mathbf{R}$ interval being 0.2 sec. 


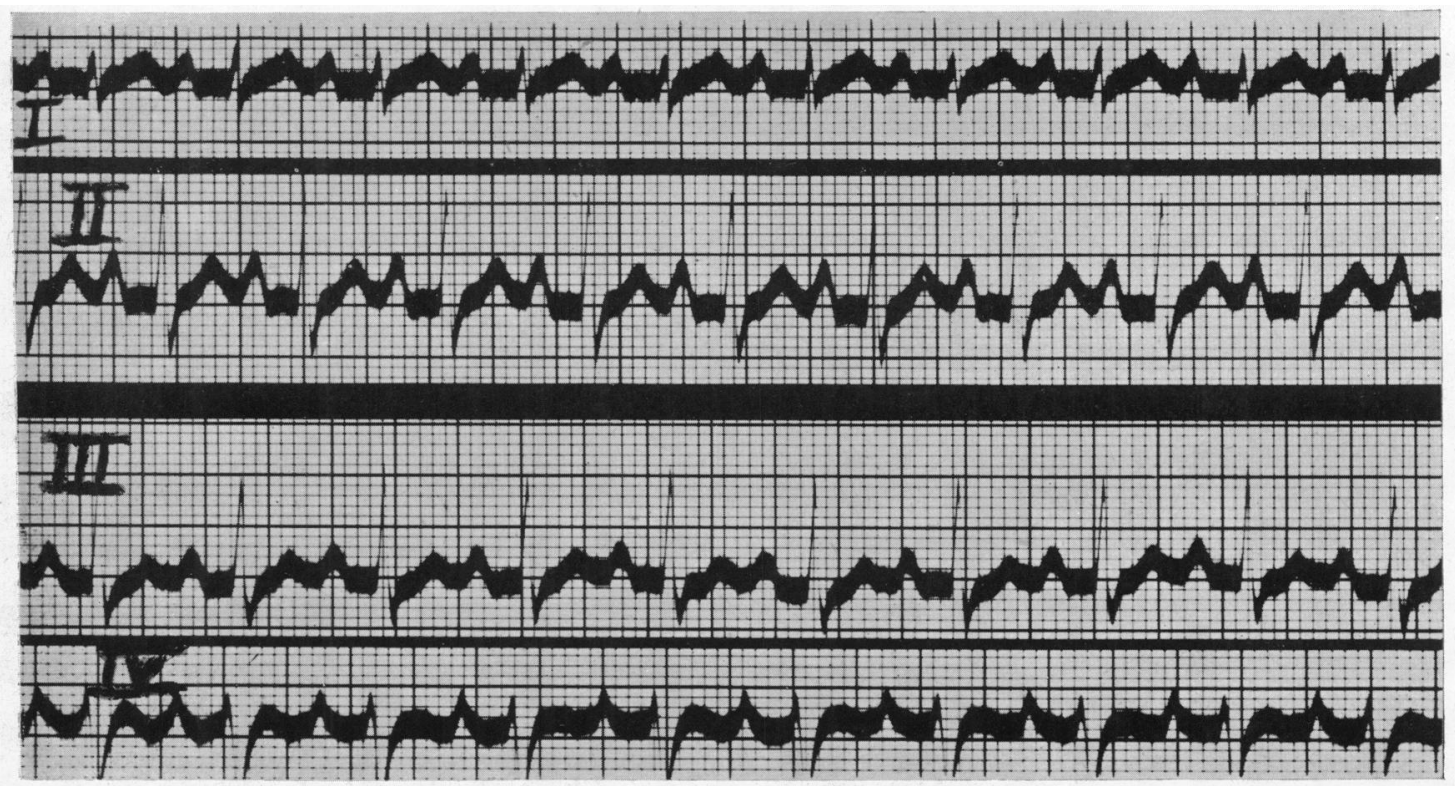

FIG. 3.-Case 2. Normal sinus rhythm. P-R interval 0.2 sec.

replacing every sixth normal beat. The pericardial friction rub could now be plainly heard all over the præcordium. On the next morning she collapsed and died in 15 minutes.

Necropsy. Moderate wasting.

Heart. Marked fibrinous pericarditis with but a small amount of fluid present. There was dilatation of both ventricles with softening of the myocardium. The mitral valve showed typical rheumatic vegetations along the line of closure, a "MacCallum patch "was present and a more generalized roughening of the endocardium of the left ventricle towards the apex. The aortic valve was incompetent with recent rheumatic vegetations on the cusps. Tricuspid and pulmonary valves appeared normal. No evidence of previous rheumatic valvulitis.

The lungs showed a few subpleural petechiæ only.

The liver was enlarged and congested, the cut surface showed " nutmeg" change.

The spleen was enlarged by one and a half times normal size, the pulp firm with prominent follicles.

The kidneys showed no gross abnormality.

Other abdominal and pelvic viscera were normal.

\section{The Diagnosis of Ventricular Escape}

In the series of cases reported there would appear to be no specific signs or symptoms that could be attributed to ventricular escape alone. White (1916) noted that one of his patients complained of palpitation and he found a cardiac irregularity that he ascribed to auricular extrasystoles. Wilson (1915) had three patients who complained of intense palpitation during experimentally produced A-V dissociation. Cutts (1937) mentions only one of his twelve cases as having subjective symptoms (" a jumping feeling in her chest ") but a number of them had unspecified cardiac irregularities. Five of the twelve had a first heart sound that varied from being softened to loud and snapping. Stein and Bartlett (1946) hold that a diagnósis cannot be made on clinical grounds, although auscultation may reveal an irregularity of rhythm similar to premature contractions or second degree heart block. There may be no irregularity recognizable clinically. Sudden rapid pulsation of the neck veins is said to be visible on occasion. All the cases described in association with acute rheumatism would appear to have developed ventricular escape early in the course of the illness.

The first described here had no symptoms and her arrhythmia was thought to be due to extrasystoles.

The second case was most unusual because, firstly, the ventricular rate was much more rapid than in others described (generally it is between 80 and 110 a minute), and the irregularity was therefore taken to be due to auricular fibrillation; and, secondly, there was acute cardiac failure with dyspnœa, œdema, and a rapidly enlarging, tender liver.

The discovery of an irregular rhythm with or without subjective symptoms; especially if associated 
with a varying quality of the first heart sound and occurring in the course of acute rheumatism, usually early, should lead one to consider the possibility of ventricular escape and have an electrocardiogram recorded.

\section{The Significance of Ventricular Escape IN ACUTe Rheumatism}

It seems generally agreed that ventricular escape occurring early in the course of acute rheumatism is transient and not in itself serious; and as all the cases with rheumatic carditis in the series quoted seem to have recovered in two months or so, it would not seem to indicate severe rheumatic carditis. Case 1 further supports this view. The ventricular escape in Case 2, however, occurring late in the course of severe rheumatic pancarditis, may have been responsible for the onset of acute cardiac failure. Furthermore although the second cardiogram taken when the rhythm was clinically regular showed no A-V dissociation, the subsequent clinical findings up to the time of death would suggest that it recurred. It is therefore suggested that in this particular case death was almost ceıtainly due to severe pancarditis, though the A-V dissociation due to the ventricular escape may possibly have hastened the end.

Further electrocardiographic studies in cases of severe rheumatic carditis with cardiac failure, even when the rhythm is clinically regular might reveal that ventricular escape is more common and of more serious import than at present supposed.

\section{SUMmARY}

Two cases of ventricular escape occurring during the course of acute rheumatism are described. One occurred early in the illness and is considered to be of little significance. The other occurred late in the course of severe pancarditis and it may have been responsible for the onset of acute cardiac failure. The auricular and ventricular rates in this case were unusually rapid.

I wish to thank Professor N. B. Capon and Dr. E. Noble Chamberlain for their helpful advice and criticism during the preparation of this paper; also Dr. W. E. Crosbie, Medical Superintendent of Alder Hey Children's Hospital for permission to publish these cases.

\section{REFERENCES}

Cutts, F. B. (1937). Amer. Heart J., 13, 453.

Dressler, W. (1930). Wien. Arch. inn. Med., 19, 611. Gross, L., and Fried, B. M. (1936). Amer. J. Path., 12,31 .

Richardson, H. B. (1915). Arch. intern. Med., 16, 517.
Wendkos, M. H., and Noll, J. (1944). Med. Clin. North America, 28, 124

White, P. D. (1916). Arch. intern. Med., 18, 244.

Wilson, F. N. (1915). Ibid., 16, 989.

Stein, I., and Bartlett, A. G. (1946). Amer. J. med. Sci., 211, 686 . 